\title{
Bronchoscopy with transbronchial biopsies: measurement of bleeding volume and evaluation of the predictive value of coagulation tests
}

\author{
$\varnothing$. Bjørtuft*, F. Brosstad**, J. Boe*
}

Bronchoscopy with transbronchial biopsies: measurement of bleeding volume and evaluation of the predictive value of coagulation tests. $\emptyset$. Bjфrtuft, F. Brosstad, J. Boe. CERS Journals Ltd 1998.

ABSTRACT: The objectives of this study were to measure the bleeding volume associated with fibreoptic bronchoscopy with transbronchial biopsies (TBB), to correlate it with coagulation tests and to compare bleeding volume in patients with and without lung transplant.

A total of 104 consecutive TBB in 51 different patients was evaluated prospectively. Before each procedure, haemoglobin, blood platelets, prothrombin time (PT), activated partial thromboplastin time (aPTT) and bleeding time were measured. During the procedure, lavage fluid and blood were collected by suction. The haemoglobin concentration of the mixture was measured and bleeding volume was calculated. Clinically significant bleeding was arbitrarily defined as $>20 \mathrm{~mL}$ blood present in lavage fluid.

The mean \pm sD bleeding volume was $7 \pm 10 \mathrm{~mL}$ with no statistically significant difference between transplanted and nontransplanted patients. In eight procedures $(\mathbf{7 . 7 \%})$ the bleeding volume was $>20 \mathrm{~mL}$ (range $22-61 \mathrm{~mL}$ ). Prebiopsy values for blood platelet counts, PT and aPTT did not predict a bleeding tendency in any of the procedures in which significant bleeding occurred. No correlation was found between bleeding time and bleeding volume in the 17 procedures performed in patients with a prolonged bleeding time ( $\breve{S} 10$ min).

The bleeding associated with transbronchial biopsies was usually minor and quantitatively similar in patients with or without lung transplant. Coagulation tests could not predict clinically significant bleeding, which may occur in patients with normal coagulation test results.

Eur Respir J 1998; 12: 1025-1027.

Fibreoptic bronchoscopy with transbronchial biopsies (TBB) is a useful tool in diagnosing lung diseases $[1,2]$ and establishing a diagnosis of rejection and/or infection in patients with heart-lung and lung transplants [3-7]. However, TBB is associated with complications such as pneumothorax, bleeding, cardiac arrhythmias and possibly respiratory failure [8-13]. Previous literature on lung biopsy-related bleeding has generally not addressed TBB, and does not provide exact figures for blood volumes lost during the procedure. Although all previous reports, which are retrospective with the exception of one study [8], show-ed that life-threatening or fatal bleeding secondary to $\mathrm{TBB}$ is a rare event, every attempt to predict and thereby prevent its occurrence should be made.

As hospital practice, every patient is screened with coagulation tests before TBB was performed, and since blood platelets play a significant role in haemostasis, bleeding time has routinely been included in this coagulation screening.

The aims of the present study were, therefore, threefold: 1) to quantify prospectively the bleeding associated with bronchoscopy and TBB; 2) to evaluate the capacity of coagulation tests such as bleeding time, platelet count, prothrombin time (PT) and activated partial thromboplastin
*Dept of Thoracic Medicine and **Coagulation Laboratory, The National Hospital, University of Oslo, Oslo, Norway.

Correspondence: $\varnothing$. Bjørtuft

Lungeavdelingen

Rikshospitalet

0027 Oslo

Norway

Fax: 472286859

Keywords: Bleeding coagulation tests

lung biopsy

Received: June 51997

Accepted after revision August 61998

Supported by the Congress Chairman's Award of the European Respiratory Society Congress in Stockholm 1996. time (aPTT) to predict clinically significant bleeding; and 3 ) to compare bleeding volume in TBB performed in patients with and without lung transplants.

\section{Patients and methods}

The bleeding associated with 104 TBB performed consecutively at our department was evaluated prospectively. The patients' diagnoses are summarized in table 1 .

Bronchoscopy was performed with an Olympus BF P20D or IT 20D (Olympus, Tokyo, Japan) under fluoroscopic control. In patients with lung transplants, biopsies were obtained using a 3-mm alligator forceps (Endo-Flex KX 0418-100, Düsseldorf, Germany). If possible, biopsies were taken from all lobes of the transplanted lung. For the remainder of the patients, 2-mm forceps (Olympus FB19C) were used. These biopsies were taken from areas with marked radiological abnormalities in one of the lungs. The number of biopsies in patients with lung transplants ranged 7-10 biopsies.patient ${ }^{-1}$, whereas $4-5$ biopsies-patient ${ }^{-1}$ were regarded as satisfactory for the patients without lung transplants. All of the bronchoscopies were performed by experienced bronchoscopists and 75 of the procedures were performed by one of the authors $(\varnothing$. Bjørtuft). 
Table 1. - Diagnoses, number of patients and number of bronchoscopies with transbronchial biopsies (TBB)

\begin{tabular}{lrrr}
\hline Diagnosis & $\begin{array}{c}\text { Patients } \\
\mathrm{n}\end{array}$ & Total TBB* \\
\hline Single lung transplantation & 24 & 69 & $(1-7)$ \\
Bilateral lung transplantation & 3 & 7 & $(1-4)$ \\
Heart-lung transplantation & 2 & 6 & $(3)$ \\
Sarcoidosis & 7 & \multicolumn{2}{c}{7} \\
Fibrosing alveolitis & 6 & \multicolumn{2}{c}{6} \\
Carcinomatosis & 2 & 2 \\
Lymphangioleiomyomatosis & 2 & \multicolumn{2}{c}{2} \\
Fibrosis due to radiation & 2 & \multicolumn{2}{c}{2} \\
therapy or nitrofurantoin & & \multicolumn{2}{c}{3} \\
Uncertain diagnosis & 3 & \multicolumn{2}{c}{3} \\
Total & 51 & 104 \\
\hline
\end{tabular}

*: presented as number and biopsies.patient ${ }^{-1}$.

During bronchoscopy, blood and saline lavage fluid were collected through a vacuum suction system connected to the bronchoscope. The volume of mixed blood and lavage fluid $(V M)$ and the haemoglobin concentration in this mixture $(\mathrm{HbM})$ were measured. Haemoglobin in the patient's blood $(\mathrm{Hbp})$ and haematocrit were measured before the procedure and the volume of blood loss was calculated using the formula: $V \mathrm{M} \times \mathrm{HbM} / \mathrm{Hb}$. A volume of $>20 \mathrm{~mL}$ was arbitrarily defined as a clinically significant bleeding.

All patients were screened before the procedure with coagulation tests including bleeding time, PT, aPTT and platelet count. Bleeding time was measured according to Ivy et al. [14] and a bleeding time of Š10 min was regarded as prolonged [14]. None of the patients had renal failure, known liver disease, a history of bleeding tendency or anticoagulants therapy.

Values are given as mean \pm SD. A two-tailed Student's ttest was used to compare groups, and a correlation coefficient ( $\mathrm{r}$ ) between bleeding volume and bleeding time was determined using Pearson's test. A p-value $<0.05$ was considered statistically significant.

\section{Results}

The number of procedures performed in different patient categories (ultimately proven diagnoses) is shown in table 1. The mean amount of bleeding in all procedures was $7 \pm 10 \mathrm{~mL}$ (range $0-61 \mathrm{~mL}$ ). Eight patients $(7.7 \%$ ) had clinically significant $(>20 \mathrm{~mL})$ bleeding, ranging $22-61$ $\mathrm{mL}$. One patient haemorrhaged $>50 \mathrm{~mL}$. None of the bleeding episodes was regarded as serious or life-threatening, in that the patient developed hypotension or required intubation or blood transfusion. There was no statistically significant difference in bleeding volume between patients with or without lung transplants (range $0-61 \mathrm{~mL}$ and $0-44 \mathrm{~mL}$, respectively) (table 2 ).
Table 3. - Number of patients, sex, age, bleeding volume and coagulation tests in all procedures and in procedures with and without significant bleeding

\begin{tabular}{lccc}
\hline & $\begin{array}{c}\text { All } \\
\text { procedures }\end{array}$ & $\begin{array}{c}\text { Procedures } \\
\text { with }<20 \mathrm{~mL} \\
\text { bleeding }\end{array}$ & $\begin{array}{c}\text { Procedures } \\
\text { with Š20 mL } \\
\text { bleeding }\end{array}$ \\
\hline $\mathrm{n}(\mathrm{F} / \mathrm{M})$ & $104(63 / 41)$ & $96(59 / 37)$ & 8 \\
Age yrs (range) & $50(25-78)$ & $50(25-78)$ & $53(34-63)$ \\
Bleeding mL & $7 \pm 10$ & $4 \pm 5$ & $36 \pm 12$ \\
Haemoglobin g.100 & $11.5 \pm 2.0$ & $11.5 \pm 2.0$ & $11.4 \pm 2.9$ \\
mL-1 & & & \\
Haematocrit & $35 \pm 6$ & $35 \pm 6$ & $34 \pm 8$ \\
$\begin{array}{l}\text { Platelets } \\
\text { Prothrombin time INR }\end{array}$ & $318 \pm 123$ & $320 \pm 126$ & $288 \pm 95$ \\
Activated partial & 1.0 & 1.0 & 1.0 \\
thromboplastin & $27 \pm 4$ & $27 \pm 3$ & $28 \pm 6$ \\
time s & & & \\
Bleeding time min & $7 \pm 4$ & $7 \pm 4$ & $7 \pm 5$ \\
\hline
\end{tabular}

Data are mean \pm SD. F: female; M: male; INR: International Normalized ratio.

Screening with coagulation tests such as blood platelets, PT and aPTT revealed no values that could indicate a potential risk of bleeding, either in the group with significant bleeding $(>20 \mathrm{~mL})$ or in the group with minor bleeding (table 3 ). However, 17 procedures (16\%) were performed with a bleeding time of Š 10 min (table 2). Three of these procedures were performed in three different, nonlung transplant patients. The remaining 14 procedures were performed in 13 different patients with lung transplants. One of the 17 procedures with a prolonged bleeding time resulted in a significant bleeding event. When the bleeding volume in the procedures performed in patients with bleeding time S 10 min was compared with the bleeding volume in procedures in patients with a bleeding time of $<10 \mathrm{~min}$, there was no statistically significant difference (table 2).

There was no statistically significant correlation between bleeding time and bleeding volume $(\mathrm{r}=0.04)$.

\section{Discussion}

The major finding of this study was that there is no correlation between coagulation tests and the likelihood of bleeding following TBB. This indicates that normal coagulation test results do not guarantee that bleeding will not occur.

These results are in accordance with the only previous paper that has addressed the relationship between coagulation test results and bleeding associated with fibreoptic bronchoscopies with biopsies [15]. KoZAK and BRATH [15] retrospectively evaluated 305 procedures and found that coagulation tests such as PT and aPTT did not predict bleeding. TBB was not distinguished from ordinary bronchial biopsies in their study.

Table 2. - Bleeding volume in different groups of patients

\begin{tabular}{lcccc}
\hline & $\begin{array}{c}\text { Patients with } \\
\text { lung transplant }\end{array}$ & $\begin{array}{c}\text { Patients without } \\
\text { lung transplant }\end{array}$ & Patients with bleeding time \\
\cline { 3 - 5 } & 82 & 22 & Š10 min & $<10$ min \\
\hline Age yrs (range) & $50(25-62)$ & $50(28-78)$ & $50(31-74)$ & $50(25-78)$ \\
Bleeding mL, mean \pm SD & $6 \pm 10$ & $7 \pm 12$ & $7 \pm 10$ & $7 \pm 10$ \\
\hline
\end{tabular}


In a comprehensive review, bleeding time was not judged to be useful in predicting haemorrhage associated with operations and renal biopsies [16]. Bleeding time has not previously been addressed in relation to transbronchial biopsies. In the present study, a prolonged bleeding time was not indicative of a general or local bleeding tendency, as no correlation was found between bleeding time and volume, indicating that the bleeding time does not predict clinically significant bleeding during TBB.

Measurement of the haemorrhage during TBB probably underestimates the actual volume of blood lost. Blood will be retained in the lung parenchyma, sometimes indicated by opacities on postbiopsy radiographs [17]. Some blood is also dispersed in the suction system, and sometimes, patients cough up blood during the procedure. Even with this in mind, the present measurements show that the bleeding associated with bronchoscopy with TBB is usually minor and $<20 \mathrm{~mL}$.

Previous reports have not established any common definition of clinically significant bleeding related to biopsies via the fibreoptic bronchoscope. Definitions of significant (terms such as "major", "profuse" and "excessive" are also used) bleeding have varied: $>50 \mathrm{~mL}$ [11], >100 $\mathrm{mL}$ [15], $>100 \mathrm{~mL}$ blood intermixed with saline lavage [10], or merely the judgement of the bronchoscopist [6]. None of these previous reports described how the measurement of blood volume was performed or the clinical situation associated with this bleeding volume. In planning the present study an arbitrary decision was made to consider a bleeding volume of $20 \mathrm{~mL}$ as clinically significant. With the accurate measurements used this would be comparable to the previously less precise volume estimates $[10,11$, 15]. Significant bleeding was found in $7.7 \%$ of the procedures, compared with $<1-19 \%$ in previous studies $[5,10$, $11]$, indicating that significant bleeding will occur regularly, but the rate depends on the definition of significance. The present data further support previous findings that life-threatening bleeding after TBB is rare $[10,13]$.

This study has shown that bleeding associated with transbronchial biopsies is similar in patients with or without lung transplant. Bleeding time is a time-consuming measurement with no apparent predictive value when it comes to bleeding associated with transbronchial biopsies and, accordingly, it is recommended that this test should not be performed routinely. Screening with coagulation tests such as prothrombin time, activated partial thromboplastin time and blood platelets do not appear to identify patients who eventually develop clinically significant bleeding, indicating that clinically significant bleeding can occur, even with normal coagulation test results and without risk factors such as a history of bleeding and anticoagulant therapy.

\section{References}

1. Mitchell DM, Emerson CJ, Collins JV, Stableforth DE. Transbronchial lung biopsy with the fibreoptic bronchoscope: analysis of results in 433 patients. Br J Dis Chest 1981; 75: 258-262.

2. Fulkerson WJ. Current concepts. Fiberoptic bronchoscopy. N Engl J Med 1984; 311: 511-515.

3. Higenbottam TW, Stewart S, Penketh A, Wallwork J. Transbronchial lung biopsy for the diagnosis of rejection in heart-lung transplant recipients. Transplantation 1988; 46: 532-539.

4. Starnes VA, Theodore J, Oyer PE, et al. Pulmonary infiltrates after heart-lung transplantation: evaluation by serial transbronchial biopsies. J Thorac Cardiovasc Surg 1989; 98: 945-950.

5. Scott JP, Fradet G, Smyth RL, et al. Prospective study of transbronchial biopsies in the management of heart-lung and single lung transplant patients. J Heart Lung Transplant 1991; 10: 626-637.

6. Trulock EP, Ettinger NA, Brunt EM, Pasque MK, Kaiser LR, Cooper JD. The role of transbronchial lung biopsy in the treatment of lung transplant recipients. Chest 1992; 102: 1049-1054.

7. Guilinger RA, Paradis IL, Dauber JH, et al. The importance of bronchoscopy with transbronchial biopsy and bronchoalveolar lavage in the management of lung transplant recipients. Am J Respir Crit Care Med 1995; 152: 2037-2043.

8. Pereira W, Kovnat DM, Snider GL. A prospective cooperative study of complications following flexible fiberoptic bronchoscopy. Chest 1978; 73: 813-816.

9. Surratt DM, Smiddy JF, Bruber B. Deaths and complications associated with fiberoptic bronchoscopy. Chest 1976; 69: 747-751.

10. Cordasco EM Jr, Mehta AC, Ahmad M. Bronchoscopically induced bleeding. A summary of nine years' Cleveland Clinic experience and review of the literature. Chest 1991; 100: 1141-1147.

11. Pue CA, Pacht ER. Complications of fiberoptic bronchoscopy at a university hospital. Chest 1995; 107: 430-432.

12. Simpson FG, Arnold AG, Purvis A, Belfield PW, Muers MF, Cooke NJ. Postal survey of bronchoscopic practice by physicians in the United Kingdom. Thorax 1986; 41: 311-317.

13. Prakash UBS, Offord KP, Stubbs SE. Bronchoscopy in North America: the ACCP survey. Chest 1991; 100: 1668 1675

14. Ivy AC, Nelson D, Buchner G. The standardization of certain factors in the cutaneous "venostatis" bleeding time technique. J Lab Clin Med 1941; 26: 1812-1822.

15. Kozak EA, Brath LK. Do "screening" coagulation tests predict bleeding in patients undergoing fiberoptic bronchoscopy with biopsy? Chest 1994; 106: 703-705.

16. Channing Rodgers RP, Levin J. A critical reappraisal of the bleeding time. Semin Thromb Hemost 1990; 16: 1-20.

17. Root JD, Molina PL, Anderson DJ, Sagel SS. Pulmonary nodular opacities after transbronchial biopsy in patients with lung transplants. Radiology 1992; 184: 435-436. 